\title{
Flu Like Symptoms, CTCAE
}

National Cancer Institute

\section{Source}

National Cancer Institute. Flu Like Symptoms, CT CAE. NCI Thesaurus. Code C143492.

A disorder characterized by a group of symptoms similar to those observed in patients with the flu. It includes fever, chills, body aches, malaise, loss of appetite and dry cough. 